\title{
Malformação em teleógina de Rhipicephalus sanguineus recolhida em ambiente intradomiciliar, no Rio de Janeiro, RJ
}

\author{
Mutagenic occurence in teleoginae of Rhipicephalus sanguineus from \\ intradomiciliary environment at Rio de Janeiro city
}

Nicolau Maués Serra-Freire ${ }^{1 *}$; Ana Beatriz Pais Borsoi ${ }^{2}$

\author{
${ }^{1}$ Laboratório de Ixodides, Referência Nacional em Taxonomia de Vetores das Riquétsias, Instituto Oswaldo Cruz - FIOCRUZ e \\ Bolsista do CNPq \\ ${ }^{2}$ Estagiária do Programa de Iniciação Científica, Instituto Oswaldo Cruz - FIOCRUZ
}

Recebido em 17 de Dezembro de 2008

Aceito em 5 de Fevereiro de 2009

\section{Resumo}

Do material recolhido por aspiração no interior de uma residência no Rio de Janeiro, com uso de aspirador de pó, por 4 horas contínuas de captura, em todos os cômodos da casa, foram encontrados 1.284 Rhipicephalus sanguineus, dos quais 289 eram fêmeas e, destas, uma tinha malformação no opistossoma que estava assimétrico, e monstruosidade pela presença de dois ânus. Esse é o primeiro registro desse fenômeno em $R$. sanguineus.

Palavras-chave: Rhipicephalus sanguineus, malformação, teratogenia.

\begin{abstract}
From material collected by into a residence house at Rio de Janeiro city, using an aspirator machine during four continues hours in all house, it was captured 1,284 Rhipicephalus sanguineus including 289 females; one of them showed a mutagenic alteration like an asymmetry of opistosome, and monstrosity like a two anus. The first register of this phenomenon in $R$. sanguineus is reported.
\end{abstract}

Keywords: tick, mutagenic occurence, asymmetry.

Malformação em carrapatos (Acari, Ixodida, Ixodidae) pode ocorrer naturalmente (LOOMIS; STONE, 1970), mas são muitas as afirmaçôes de que pode ser induzida por compostos químicos usados no combate aos carrapatos (ARAGÃO, 1936; NEVEU-LEMAIRE, 1938; GRAHAM; PRICE, 1966; MORÁN RAMOS, 1976). Anomalias morfológicas também já foram descritas, considerando-se como causalidade a formação de indivíduos híbridos entre espécies do mesmo gênero (GRAHAM; PRICE, 1966).

As malformaçôes mais comuns, citadas em literatura, ocorridas em carrapatos são: maior ou menor número de patas, com perda de simetria no espécime (ARAGÃO, 1936; GOUVEA SOUTO, 1939; SILVA, 1982); aparecimento de olhos suplementares (NEUMANN, 1899); desvio de placa peritremática (GOUVEA SOUTO, 1939); assimetria da dentição hipostomal, dos palpos, quelíceras e escudo (NEVEU-LEMAIRE, 1938). Teratologia com ginandromorfismo foi descrita em Amblyomma cajennense (Fabricius, 1787)(FONSECA, 1935) e em Boophilus kohlsi Hoogstraal e Kaiser, 1960 (LOOMIS; STONE, 1970). Monstruosidades como o aparecimento, no mesmo espécime, de dois ânus, três

\footnotetext{
*Autor para correspondência: Nicolau Maués Serra-Freire

Laboratório de Ixodides, Referência Nacional em Taxonomia de Vetores das Riquétsias, Instituto Oswaldo Cruz - FIOCRUZ, Av. Brasil, 4365, Manguinhos, CEP 21040-360 Rio de Janeiro - RJ, Brasil; e-mail: nmsf@ioc.fiocruz.br
}

estigmas ou dois apêndices caudais já foram registrados por (NEVEU-LEMAIRE, 1938), ou mesmo a ausência de ânus (SILVA, 1982). Malformações em órgãos internos também já foram descritas em Hyalomma plumbeum (Panzer, 1785) Vlasov, 1940 (KAN; SMIRNOVA, 1975).

Dados sobre alteraçóes morfológicas consequentes aos fenômenos de muda e ecdise são poucos, merecendo destaque a informação de LARANJA (1979), que calculou ser de $0,23 \%$ o coeficiente de malformação em Boophilus microplus (Canestrini, 1887), ao avaliar amostra com 36.461 teleóginas e as larvas emergidas dos ovos após incubação. Também com B. microplus (SACO, 1982), estimou em $1,52 \%$ o coeficiente de malformação em partenóginas e teleóginas.

Dentre os produtos carrapaticidas já reconhecidos como indutores de teratogenia, ou de mutagenia, como as chamadas malformaçóes e monstruosidades em Ixodida, estáo: triclorfon, dicresil éster do ácido $\mathrm{N}$-metilcarbâmico, clorpirifós (KAN; SMIRNOVA, 1975), amitraz (SACO, 1982), organofosforado (SALEH, 1980; IOCHPE, 1982) e todos os carrapaticidas em geral, dependendo do poder de pressão de uso (SILVA, 1982).

Como uma das consequências da evolução social e cultural da população brasileira nas grandes capitais e centros urbanos, o convívio com animais de companhia tem sido estreitado, e, em alguns casos, cães e gatos vêm sendo criados como entes familiares 
dos humanos, ocupando todos os espaços do lar, inclusive cama de dormir, mesa de refeiçôes, banheiros e cozinha. Dessa maneira, houve aumento dos registros de carrapatos dentro das residências humanas, o que motivou a proposição do projeto para avaliar a situação da colonização do intradomicílio por carrapatos, em espaço político administrativo da cidade do Rio de Janeiro, área urbana, com avaliação de risco para humanos e outros vertebrados ocupantes das residências.

$\mathrm{Na}$ cidade do Rio de Janeiro, foi utilizada a estratégia do Programa de Controle de Zoonoses Urbanas para controlar a população excedente de cães e gatos em vias públicas. Esse monitoramento foi desenvolvido em parceria com a Prefeitura da Cidade do Rio de Janeiro, representada como executivo pela Secretaria Especial de Promoção e Defesa dos Animais (SEPDA) e a Universidade Estácio de Sá, tendo como executor o Curso de Medicina Veterinária. Assim buscou-se localizar domicílio com elevado nível de infecção por carrapatos, já identificado pelos moradores, e que se mostrassem sensíveis a participar do estudo, autorizando as investigaçóes sobre os carrapatos no intradomicílio.

Dessa forma, chegou-se a uma residência construída em alvenaria, de único piso, cercada por muro emboçado com pintura desgastada, tendo jardim e quintal intercomunicados por garagem. No jardim, plantas ornamentais em vasos e em canteiro contíguo ao muro dos dois lados; no quintal, duas árvores de médio porte, uma com copa cônica e a outra com copa em disco; no solo há grama batatais. A casa tem piso frio, paredes emboçadas e pintura desgastada pelo tempo; todas as janelas protegidas internamente com cortinas longas, e o piso protegido com tapetes de linha; muitos móveis ocupam grande parte da área construída, e muitos ficam encostados às paredes.

A residência é ocupada por seis pessoas, sendo duas crianças, dois adultos, dois idosos e dois cáes de porte médio, sem raças definidas, que transitam livremente entre o intra e o extradomicílio, inclusive tendo acesso à via pública. Pela descrição da proprietária, a casa recebe uma faxina completa a cada dois meses, e é varrida de dois em dois dias nos espaços livres de móveis; cozinha e banheiro são limpos diariamente com pano molhado. Por medida de segurança, as janelas raramente são abertas. A porta da frente fica fechada, só abrindo para passagem das pessoas e, a dos fundos, fica sempre aberta de dia.

Os pratos de comida dos cáes sáo individuais e servidos na cozinha, tendo um único bebedouro para os dois animais; cada cão dorme em um dos quartos da casa, acompanhando as crianças e os idosos. Esses cães são vacinados nas campanhas de vacinação contra raiva, são banhados de 15 em 15 dias com água e sabão, não sendo usados xampus, remédios na pele e injeçôes; os animais são considerados como tendo saúde e não são levados a veterinários. Somente carrapatos e algumas vezes pulgas são observados sobre os cães, mas parece que não os incomoda, no dizer dos moradores da residência.

Foi realizada uma coleta de material no interior da residência, utilizando um aspirador de pó doméstico munido de saco de pano recolhedor do pó aspirado. Foi aspirado o chão de todos os cômodos da casa, paredes até a laje do teto, inclusive atrás dos móveis que foram desencostados das paredes. $\mathrm{O}$ material recolhido no saco de pano do aspirador foi colocado dentro de um saco plástico que teve a boca lacrada e, assim, foi transportado até o Laboratório de Ixodides no Instituto Oswaldo Cruz - FIOCRUZ. No Laboratório, o conteúdo do saco de pano foi passado para placas de Petri, onde se realizou a triagem do material, recolhendo-se os carrapatos que foram imersos em solução fungicida onde permaneceram 3 minutos. Após o banho fungicida, os carrapatos foram enxaguados com água corrente, mortos por imersão em água quente, aproximadamente a $70{ }^{\circ} \mathrm{C}$ e preservados em etanol $70^{\circ} \mathrm{GL}$.

Os carrapatos preservados foram examinados por estereomicroscopia para identificação específica de adultos e ninfas, com auxílio da chave dicotômica de Robinson (1926), Aragão e Fonseca (1961) e Flechtmann (1973). Os trabalhos de Jones et al. (1972), Famadas et al. (1994), Amorim e Serra-Freire (1999), Walker et al. (2000) e Labruna et al. (2005) foram as referências para a identificação das larvas que foram examinadas por microscopia de luz, após a montagem de lâminas.

As estatísticas descritiva e analítica foram realizadas de acordo com Serra-Freire (2002).

Da única coleta de material na residência foram recolhidos 1.284 carrapatos, sendo 496 adultos, dos quais 289 fêmeas, 207 machos; 516 ninfas, e 272 larvas, todos Rhipicephalus sanguineus (Figura 1). Desse total, uma teleógina estava com monstruosidade e malformaçáo do opistossoma, caracterizada pela presença de uma fenda larga sagital no plano antero-posterior, sentido póstero-anterior, provocando o aspecto de opistossoma bífido e com assimetria, pois a metade direita (hemi-opistossoma direito) é maior do que à esquerda (hemi-opistossoma esquerdo) (Figura 2). O escudo dorsal é mais curto do lado esquerdo, conferindo assimetria (Figura 3). A monstruosidade está na presença de três placas peritremáticas, uma atrás de cada pata IV e a outra na fenda que divide parcialmente o opistossoma (Figura 4); e de dois ânus, um em cada hemi-opistossoma, cada um desses com sulco anal posterior ao ânus (Figuras 5 e 6 ).

Considerando-se que os responsáveis pelos cães garantem que não usam qualquer produto químico para combater os carrapatos e pulgas, e que a quantidade de carrapatos recolhidos em um único esforço de captura na casa sinaliza ser verdadeira a afirmação deles, é possível admitir que a malformação da teleógina tenha sido espontânea, natural dentro do coeficiente de malformação estimado para B. microplus, representando os Ixodidae (LARANJA, 1979; SACO, 1982). No entanto, não se pode deixar de considerar que bases químicas usadas repetidamente como carrapaticidas podem

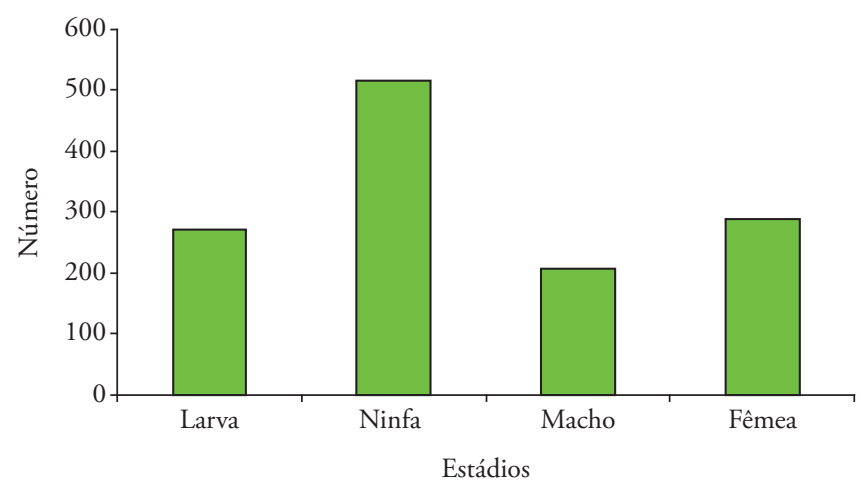

Figura 1. Relação entre as quantidades dos estádios de Rhipicephalus sanguineus Latreille, 1829, coletados em um esforço de captura em residência na cidade do Rio de Janeiro, RJ, em fevereiro de 2006. 


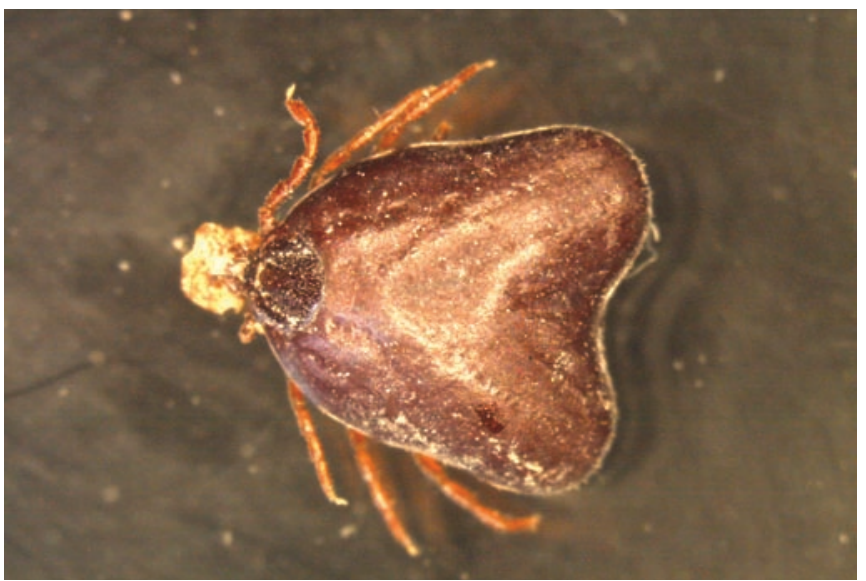

Figura 2. Visão dorsal do aspecto bífido do opistossoma de teleógina de Rhipicephalus sanguineus Latreille, 1829, coletada com malformaçáo, em uma residência na cidade do Rio de Janeiro, RJ, em fevereiro de 2006.

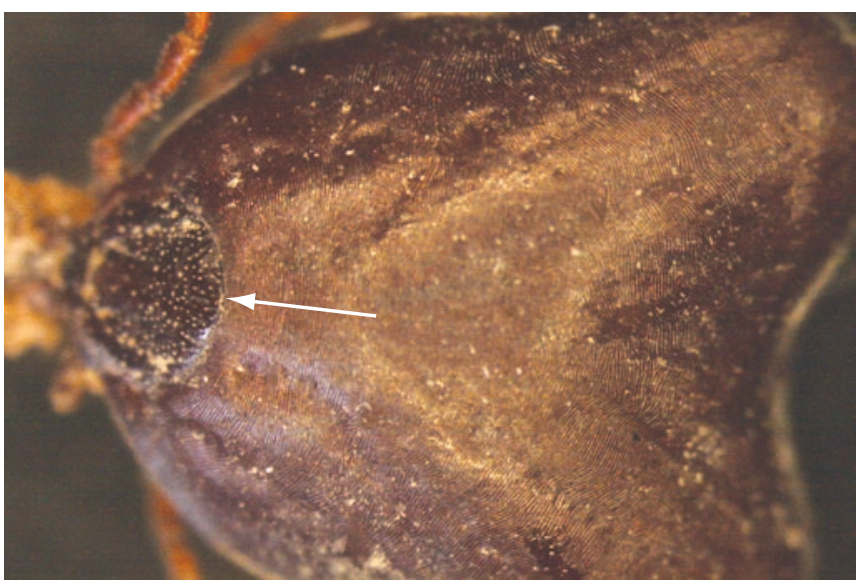

Figura 3. Aspecto assimétrico do escudo dorsal de teleógina de Rhipicephalus sanguineus Latreille, 1829, coletada com malformação, em uma residência na cidade do Rio de Janeiro, RJ, em fevereiro de 2006.

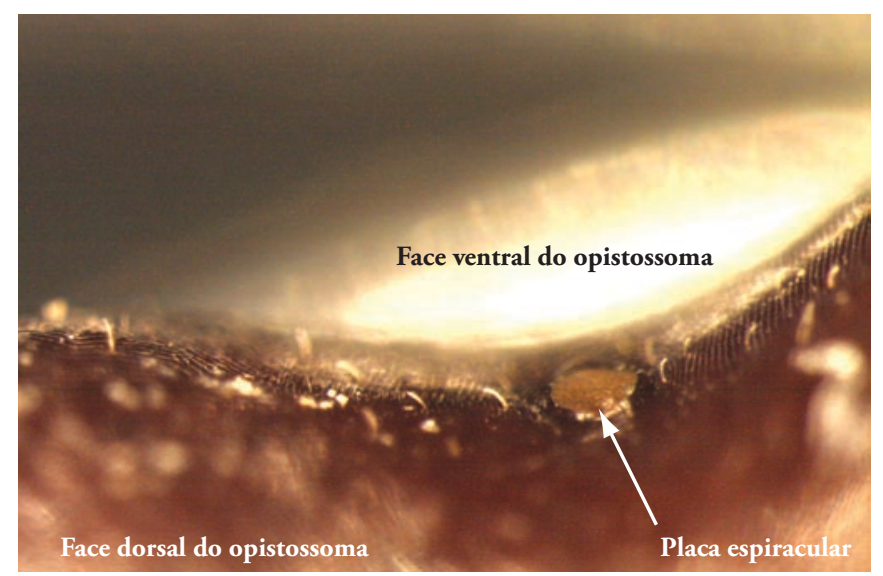

Figura 4. Aspecto da placa peritremática sagital posterior no opistossoma, entre os dois hemilobos do opistossoma bífido, em teleógina de Rhipicephalus sanguineus Latreille, 1829, coletada com malformaçáo, em uma residência na cidade do Rio de Janeiro, RJ, em fevereiro de 2006.

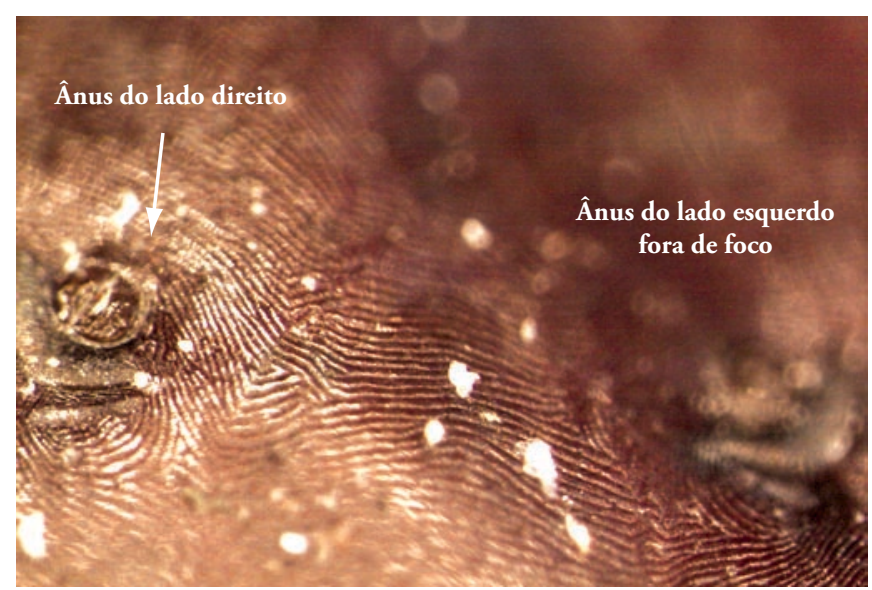

Figura 5. Aspecto ventral do opistossoma com o ânus direito, com sulco pós-anal, em teleógina de Rhipicephalus sanguineus Latreille, 1829, coletada com malformação, em uma residência na cidade do Rio de Janeiro, RJ, em fevereiro de 2006.

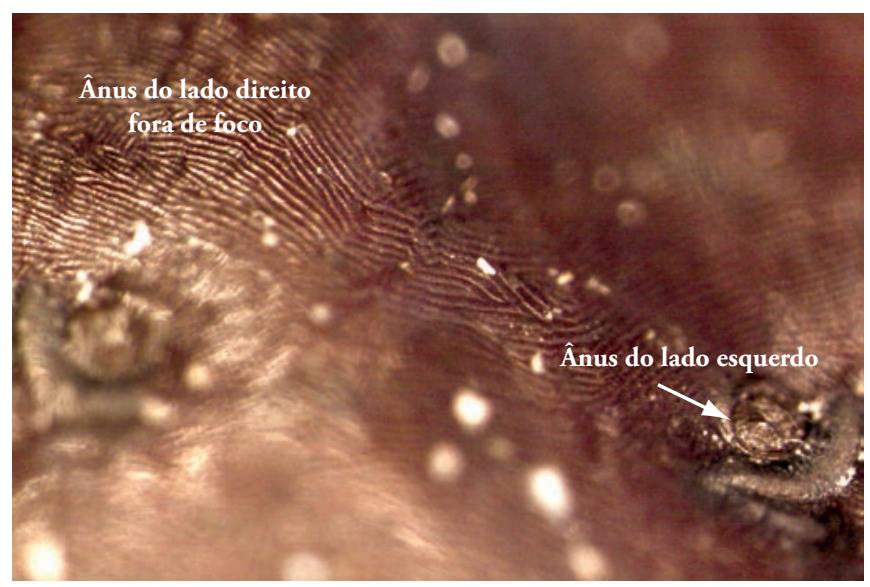

Figura 6. Aspecto ventral do opistossoma com o ânus esquerdo, com sulco pós-anal, em teleógina de Rhipicephalus sanguineus Latreille, 1829, coletada com malformação, em uma residência na cidade do Rio de Janeiro, RJ, em fevereiro de 2006.

evidenciar algum efeito teratológico ou mutagênico (MIYAMOTO, 1976), ou mesmo os subprodutos da degradação dos mesmos (RASHID, 1979). Muitas dessas bases são também usadas como inseticidas domésticos, produzidas em concentraçôes com segurança para não manifestação de efeitos indesejáveis. Porém, muitas vezes, a população desrespeita a informação do fabricante e usa o produto em concentraçóes bem maiores do que as recomendáveis, gerando considerável interesse a respeito dos possíveis riscos (PHILIP; SCOTT, 1974; MARI et al., 1976; SALEH, 1980).

No presente estudo, não foi avaliado o uso de inseticidas pelos moradores da residência estudada, ou por seus vizinhos com produtos em aerossóis que poderiam estar chegando eolicamente até o ambiente de estudo. Considerando-se que ainda não houve descrição de teratologia, monstruosidade ou malformação em $R$. sanguineus, o achado desta teleógina levanta a necessidade de maiores estudos direcionados para a avaliação do uso de inseticidas e carrapaticidas como fatores condicionantes para as teratogenias e mutagenias em artrópodes como sinalizadores, e em vertebrados como doentes com incapacidades permanentes. 


\section{Referências}

AMORIM, M.; SERRA-FREIRE, N. M. Chave dicotômica para identificação de larvas de algumas espécies do gênero Amblyomma Koch, 1844 (Acari: Ixodidae). Entomologia y Vectores, v. 6, n. 1, p. 75-90, 1999.

ARAGÃO, H. B. Ixodidas brasileiros e de alguns países limítrophes. Informações sobre algumas espécies brasileiras de ixodidas. Memórias do Instituto Oswaldo Cruz, v. 31, n. 4, p. 821-823, 1936.

ARAGÃO, H. B.; FONSECA, F. Notas de Ixodologia VIII. Lista e chave para os representantes da fauna ixodológica brasileira. Memórias do Instituto Oswaldo Cruz, v. 59, n. 2, p. 116-148, 1961.

FAMADAS, K. M.; LANFREDI, R. M.; SERRA-FREIRE, N. M. Perianal integument of the nymph and adults stage of Amblyomma cajennese (Fabricius, 1787) (Acari: Ixodidae): a new cuticular structure by scanning electron microscopy. Memórias do Instituto Oswaldo Cruz, v. 89, n. 4, p. 571-573, 1994.

FLECHTMANN, C. H. W. Ácaros de importância Médico Veterinária. São Paulo: Ed. Nobel, 1973. 192 p.

FONSECA, F. Notas de acareologia XII. Gymnandromorphismo em Amblyomma cajennense (Fabricius, 1787). Memórias do Instituto Butantan, v. 10, p. 38-41, 1935.

GOUVEA SOUTO, G. Sobre uma interessante anomalia observada em Boophilus microplus (Canestrini, 1888). Boletim da Sociedade Brasileira de Medicina Veterinária, v. 9, n. 2, p. 109-110, 1939.

GRAHAN, O. H.; PRICE, M. A. Some morphological variations in Boophilus microplus (Acarina: Ixodidae) from northern Mexico. Annals of Entomology Society of America, v. 59, n. 3, p. 450-452, 1966.

IOCHPE, A. B. Efeitos mutagênicos, carcinogênicos e teratogênicas dos pesticides. In: CURSO DE ATUALIZAÇÃO EM TOXICOLOGIA DOS PESTICIDAS, 1., 1982, Porto Alegre. Anais... Porto Alegre: CRMV-RS; Comissão de Ecologia, 1982. p. 31-32.

JONES, E. K. et al. The ticks of Venezuela (Acarina: Ixodoidea), with a key to the species of Amblyomma in the western hemisphere. Brigham Young University Science Bulletin, v. 27, n. 4, p. 1-40, 1972.

KAN, P. T.; SMIRNOVA, O. I. Toxic effect of some insecticides on ticks (morphological changes in tick tissues). Institut Veterinarnoi Sanitarii, v. 51, p. 82-91, 1975.

LABRUNA, M. B. et al. Ticks (Acari: Ixodidae) on wild carnivores in Brazil. Experimental Applied Acarology, v. 36, n. 1, p. 149-163, 2005.

LARANJA, R. J. O poder infestante da larva do Boophilus microplus (Canestrini, 1888) em diferentes condiçóes e períodos de envelhecimento. 1979. 31 f. Dissertação (Mestrado em Medicina
Veterinária - Parasitologia) - Universidade Federal do Rio Grande do Sul, Porto Alegre.

LOOMIS, E. C.; STONE, B. F. Gynandromorphs of Boophilus microplus ticks (Acarina: Ixodidae). Journal of Australian Entomology, v. 9, p. 68-70, 1970.

MARI, J. J. et al. Malformaciones congênitas em ovinos relacionadas a la administración de metil-5(6)butil-2benzimidazol carbamato (Parbendazole) em el Uruguay. Veterinaria, v. 12, n. 6, p. 123-129, 1976.

MIYAMOTO, J. Degradation metabolism and toxicity of synthetic pyrethroids. Environmental Health Perspective, v. 112, n. 14, p. 15-28, 1976.

MORÁN RAMOS, C. G. Anomalias em garrapatas Boophilus microplus (Canestrini, 1887). In: Ministerio del Desarollo Agropecuario. (Org.). Investigaciones realizadas em el campo de la parasitologia veterinária. Panamá: Universidad del Panamá, 1976. p. 64-69.

NEUMANN, G. Révision de la famille Ixodidés. Mémoires de la Société. Zoologique de France, v. 12, p. 324-420, 1899.

NEVEU-LEMAIRE, M. Traité d'entomologie medicale et veterinaire. Paris: Ed. Vigot Fréres, 1938. p. 341-344.

PHILIP, J. R.; SCOTT, G. C. The effects of methyl-5(6)-butyl2-benzimidazole carbamate (Parbendazole) on reproduction in sheep and other animals. Cornell Veterinary, v. 64, n. 4, p. 109-110, 1974.

RASHID, K. A. The relationship between mutagenic and DNA: damaging activity of pesticides and their potencial for carcinogenesis. Diseases Abstracts International, v. 39, n. 10, p. 4726-B, 1979.

ROBINSON, L. E. Ticks: a monograph of the Ixodoidea IV - The genus Amblyomma. London: Cambridge University Press, 1926. 302 p.

SACO, A. M. S. Malformaçóes em Boophilus microplus (Canestrini, 1887) sob açáo do amitraz. 1982. 76 f. Dissertação (Mestrado em Medicina Veterinária - Parasitologia) - Universidade Federal do Rio Grande do Sul, Porto Alegre.

SALEH, M. A. Mutagenic and carcinogenic effects of pesticides. Journal of Environment Science Health, v. 15, n. 6, p. 907-927, 1980.

SERRA-FrEIRE, N. M. Planejamento e Análise de Pesquisa Parasitológica. Niterói: Ed. UFF, 2002. 199 p.

SILVA, N. L. Prevalência de Boophilus microplus (Canestrini, 1887) com malformaçóes anatômicas externas, em diferentes regióes do Rio Grande do Sul. 1982. 103 f. Dissertação (Mestrado em Medicina Veterinária - Parasitologia) - Universidade Federal do Rio Grande do Sul, Porto Alegre.

WALKER, J. B.; KEIRANS, J. E.; HORAK, I. G. The genus Rhipicephalus (Acari: Ixodidae): a guide to the Brown Ticks of the World. London: Cambridge University Press, 2000. 643 p. 